\title{
Laparoscopic management of biliary obstruction secondary to sarcoidosis
}

\author{
P. Hamby ${ }^{1}$, A. Reizenman ${ }^{2}$, J. Patrick Walker*1,3 \\ ${ }^{1}$ Department of Surgery, University of Texas Medical Branch, Galveston, Texas, United States \\ ${ }^{2}$ University of Tennessee Health Science Center, Memphis, Tennessee, United States \\ ${ }^{3}$ Timberlands Healthcare, Crockett, Texas, United States
}

Received: November 8, 2016

DOI: $10.5430 /$ css.v3n1p25
Accepted: January 15, $2017 \quad$ Online Published: February 4, 2017

URL: http://dx.doi.org/10.5430/css.v3n1p25

\begin{abstract}
Evaluation of the patient presenting with an elevated bilirubin often involves a study of the biliary tract for potential obstruction. Potential etiologies for obstruction of the common bile duct (CBD) include choledocholithiasis, pancreatic or ampullary neoplasm, cholangiocarcinoma, or extrinsic compression. Extrinsic compression can be from the gallbladder itself (Mirizzi's syndrome) or a neoplasm in adjacent lymph nodes. We describe an unusual cause of CBD obstruction - sarcoidosis; as well as the workup, and the laparoscopic treatment of regional sarcoidosis.
\end{abstract}

Key Words: Common bile duct obstruction, Sarcoid, Laparoscopy

\section{INTRODUCTION}

Sarcoidosis is a condition of granulomatous inflammation most commonly associated with the skin and lungs. ${ }^{[1]}$ It was first described in its cutaneous form by Johnathan Hutchinson in 1877 in his "Illustrations from Clinical Surgery",[2,3] (see Figure 1). Later in 1898, Caesar Boeck coined the term "Sarkoid" as he viewed the lesions histologically reminiscent of sarcoma. ${ }^{[4]}$ Today, sarcoidosis remains a relatively rare autoimmune condition with an annual incidence of 5-40 cases per 100,000. ${ }^{[1,5]}$ Although associated with the lungs, sarcoidosis is well known to affect the liver. Approximately $10 \%$ of cases of sarcoidosis present as obstructive jaundice, cholecystitis, portal hypertension, cirrhosis and liver failure. ${ }^{[6]}$ Hepatic sarcoidosis is a particular diagnostic challenge because of its clinical and radiographic similarity to primary sclerosing cholangitis (PSC), pancreatic cancer and cholangiocarcinoma. In the literature, there are multiple case reports describing surgical and non-surgical management of hepatic sarcoidosis. Here we present a novel case of sarcoidosis causing biliary duct obstruction that was diagnosed and managed laparoscopically using minimally invasive techniques. We also discuss relevant literature associated with the management of hepatic sarcoidosis.

\section{CASE PRESEntation}

Our patient is a 69-year-old Caucasian female having a past medical history of hypothyroidism and hypertension, who presented to our clinic with complaints of right upper quadrant pain associated with nausea. Her symptoms had been present for several months and were exacerbated by oral intake and fatty foods. She related no history of jaundice, icterus, fevers or weight loss. She has had no previous surgery. Her physical examination was unremarkable, with the exception of moderate right upper quadrant and

\footnotetext{
*Correspondence: J. Patrick Walker; Email: jpatrickwalker@ rocketmail.com; Address: Timberlands Healthcare, Crockett, Texas; University of Texas Medical Branch, Galveston, Texas, United States.
}

Published by Sciedu Press 
epigastric abdominal tenderness. Initial laboratory values showed an elevated alkaline phosphatase of 249 U/L (normal 37-125 U/L), and a normal total bilirubin and transaminases. Abdominal ultrasound showed gallbladder wall thickening, intra and extrahepatic bile duct enlargement, with a common bile duct (CBD) measuring $1.5 \mathrm{~cm}$. A computed tomography (CT) abdomen confirmed intra and extrahepatic ductal dilation but was otherwise unremarkable. CA 19-9 was drawn and elevated at $148.8 \mathrm{U} / \mathrm{ml}(0-37 \mathrm{U} / \mathrm{ml}$ normal $)$. Serum angiotensin converting enzyme (SACE) was normal at 47 (8-52 normal). A CT of the chest was normal.

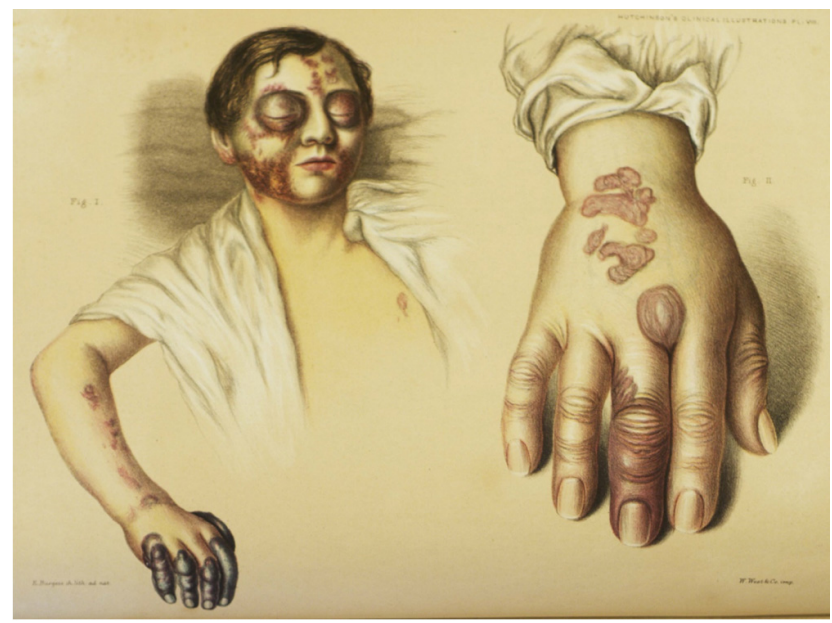

Figure 1. Original depiction of cutaneous form of sarcoidosis in "Illustrations from Clinical Surgery" by Jonathan Hutchinson ${ }^{[3]}$

Courtesy of: University of Texas Medical Branch, Galveston, Texas. Moody Medical Library, Rare Book Room.

The patient was taken to surgery for a laparoscopic cholecystectomy with intraoperative cholangiogram (IOC). The procedure was technically uncomplicated. The cholangiogram (see Figure 2), revealed a mid CBD stricture, concerning for cholangiocarcinoma or PSC. The patient recovered uneventfully from surgery. Endoscopic retrograde cholangiopancreatography (ERCP, see Figure 3) with sphincterotomy and stent placement were obtained. Ductal brushings were negative for malignant cells. Subsequent endoscopic ultrasound (EUS) showed a smooth peri-duodenal mass measuring $3.5 \mathrm{~cm} \times 1.5 \mathrm{~cm}$ causing extrinsic CBD compression.

The patient was returned to the operating room for planned laparoscopic biopsy and excision of the lesion. The mass was just posterior and superior to the $1^{\text {st }}$ portion of the duodenum. We mobilized the hepatic flexure and performed a Kocher maneuver. This provided us with excellent exposure of the common and hepatic ducts. The lesion was identified just posterior to mid CBD, and with careful dissection we excised the mass. The pathology (see Figure 4), showed classic noncaseating granulomatous disease consistent with sarcoidosis. There were no malignant cells identified. Specimens were negative for acid fast bacilli (AFB) and fungal organisms.

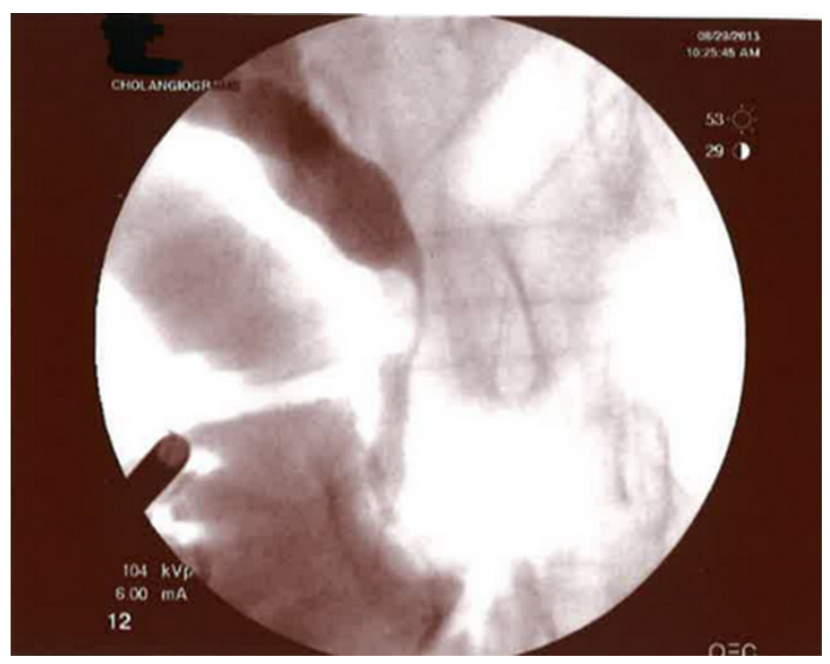

Figure 2. Cholangiogram obtained during cholecystectomy showing prominent common hepatic ductal obstruction

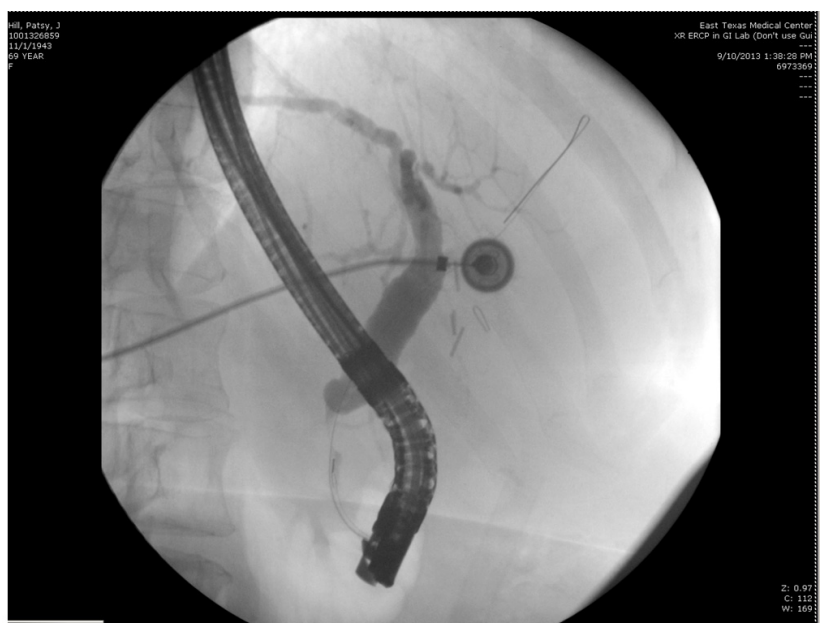

Figure 3. ERCP showing distal CBD stricture

The patient recovered well after surgery. Her symptoms had already resolved after her initial cholecystectomy. She was started on corticosteroid treatment for sarcoidosis. Her biliary stent was removed 6 weeks after surgery. She has been followed for two years with complete resolution of her symptoms and no recurrence of her sarcoid.

\section{Discussion}

Hepatic granulomatous involvement is seen in 30\%-70\% of patients with sarcoidosis. ${ }^{[7,8]}$ Symptomatic hepatic sarcoido- 
sis is relatively rare. Only an estimated $10 \%$ of patients with granulomatous hepatic involvement will actually develop biliary pathology. ${ }^{[6]}$ Our literature search identified 14 articles from 1954 to 2013, describing 18 cases of biliary obstruction from sarcoidosis. These are summarized in Table 1. A persistent theme seen in many of these cases, is highly morbid surgical procedures done for relatively benign and self-limited disease.

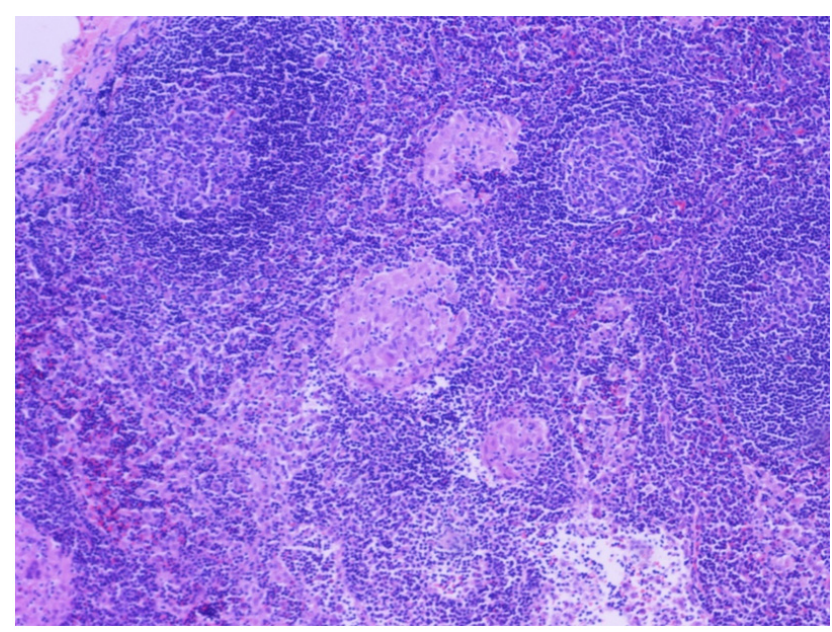

Figure 4. Histologic image of lymph node obtained from porta hepatis showing classic non-caseating granulomatous disease found in sarcoidosis

The first case as described by Ryrie ${ }^{[9]}$ in 1954 , was a 52 -yearold female who developed progressive nausea, vomiting, jaundice and icterus. Her examination was notable for hepatomegaly and a large palpable gallbladder (Courvoisier's sign). A preoperative chest $x$-ray did show mediastinal lymphadenopathy. She underwent exploratory laparotomy and was found to have a large pancreatic head mass concerning for pancreatic cancer and lymphadenopathy in the porta hepatis. The lymph nodes were biopsied and a palliative biliary diversion (cholecystoduodenostomy) was performed. Postoperative pathology showed sarcoid nodules. The patient was treated with corticosteroids and she clinically improved following procedure and medical treatment.

More recently in 2004, Peyre et al. ${ }^{[10]}$ described a case of a 57-year-old female who presented to the emergency room with a three-week history of jaundice and pruritus. Her workup was concerning for cholangiocarcinoma, with stricture found at the confluence of the cystic and hepatic ducts in ERCP. Pathology from ductal brushings were negative. She underwent exploratory laparotomy and was found to have several firm lymph nodes in the porta hepatis. The lymph nodes were biopsied and a biliary diversion (Roux-en-Y hepaticojejunostomy) was performed. Frozen sections were obtained at time of surgery and showed sarcoid granulomatous disease, which was confirmed on final pathology. Post operatively, she was treated medically with corticosteroids and improved.

In 2013 Buxbaum et al. ${ }^{[11]}$ described a case of a 42-yearold male who presented with jaundice and weight loss. His workup was notable for computed tomographic (CT) imaging showing biliary obstruction and high grade extrahepatic biliary duct obstruction seen on ERCP. He underwent exploratory laparotomy and pancreaticoduodenectomy (Whipple's procedure). Post-operative pathology showed sarcoid granulomas within specimen and porta hepatic lymph nodes. There was no evidence of malignancy. The patient was treated with corticosteroids and improved clinically.

The literature also describes several cases of hepatic sarcoidosis presenting similarly to PSC. Alam et al. ${ }^{[12]}$ reported a case of a 34 year-old female who presented with jaundice and weight loss. Her workup was notable for ERCP showing stricture of right hepatic duct and less prominent stricture of the distal intrahepatic ducts. A percutaneous liver biopsy in this case yielded granulomatous disease consistent with sarcoidosis. The patient was quickly and completely responsive to steroid treatment. In their discussion, Alam et al. ${ }^{[12]}$ cited this steroid responsiveness as evidence for sarcoidosis as opposed to PSC, although they note that the possibility of clinical overlap does exist.

Finally, Tombazzi and associates ${ }^{[13]}$ reported two cases of successful orthotopic liver transplantation (OLT) for patients with suspected PSC who were later found to have granulomatous obstruction from sarcoidosis on final pathology. In neither case is there note of attempted corticosteroid treatment for sarcoidosis. Sitiropolos ${ }^{[11]}$ and Buxbaum ${ }^{[14]}$ also reported cases of sarcoidosis with similar PSC reminiscent findings.

Overall, in summarizing the available case reports, 6 of 18 (33\%) patients with biliary sarcoidosis had a prior diagnosis of sarcoidosis at time of presentation. Our case was similar to the majority, as our patient did not have a diagnosis of sarcoidosis preoperatively. Improvement with medical therapy is documented in 15 of 18 cases. Fourteen out of 18 cases underwent some type of surgical procedure (78\%), 9 patients underwent exploratory laparotomy with two pancreaticoduodenectomy (Whipple) procedures and two biliary diversions. No complications were reported in any of the case studies. There were four cases where surgery was avoided and patient was correctly treated medically for hepatic sarcoidosis. In three of these cases a diagnosis of sarcoidosis was established with a percutaneous biopsy. One case was suspected based on a history of sarcoidosis. 
Table 1. Summary of case studies describing biliary duct obstruction secondary to sarcoidosis

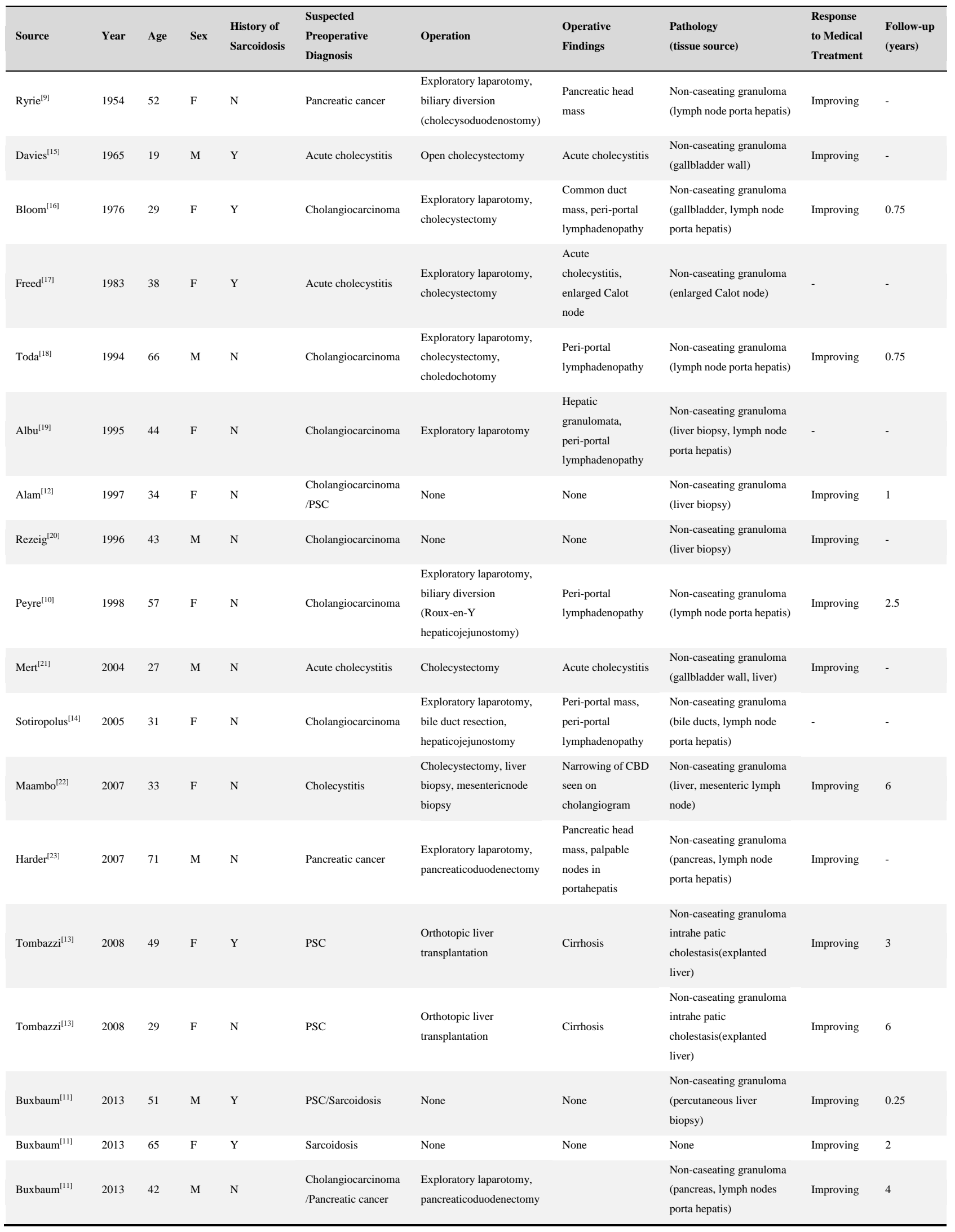




\section{Conclusions}

Symptomatic hepatic sarcoidosis is a relatively rare clinical entity. It is often unsuspected, and because of its similarity to PSC, cholangiocarcinoma and pancreatic cancer, results in unnecessary surgical procedures. The mainstay treatment of sarcoidosis has been and remains medical therapy with corticosteroids. Our study presents a unique approach to management. Using minimally invasive surgery with advanced laparoscopic techniques, we were able to confirm a diagnosis of sarcoidosis and treat our patient with minimal morbidity.

\section{CONFlicts of InTEREST Disclosure}

The authors declare they have no conflict of interest.

\section{REFERENCES}

[1] Iannuzzi MC, Rybicki BA, Teirstein AS. Sarcoidosis. N Engl J Med. 2007; 357: 2153-2165. PMid: 18032765. https://doi.org/10.1 056/NEJMra071714

[2] James DG. Centerary Commemoration of Sarcoidosis and of Jonathan Hutchinson. Br Med J. 1969; 2: 109-110. PMid: 4887040. https://doi .org/10.1136/bmj .2.5649.109

[3] Hutchinson J. Illustrations of Clinical Surgery. Churchill, London. 1877: 42.

[4] Boeck C. Multiple Benign Sarkoid of the Skin. J Cutan Genitourin Dis. 1899; 17: 543-550.

[5] Pietinalho A, Hiraga Y, Hosoda Y, et al. The frequency of sarcoidosis in Finland and Hokkaido, Japan: a comparative epidemiological study. Sarcoidosis 1995; 12: 61-7. PMid: 7617979.

[6] Ishak KG. Sarcoidosis of the Liver and Bile Ducts. Mayo Clin Proc. 1998; 73: 467-472. https://doi .org/10.1016/S0025-6 196 (11) 63733-6

[7] Branson JH, Park JH. Sarcoidosis - Hepatic Involvement: Presentation of a Case with Fatal Liver Involvement, Including Autopsy Findings and Review of the Evidence for Sarcoid Involvement of the Liver as Found in the Literature. Ann Intern Med. 1954; 40: 111-145. https://doi.org/10.7326/0003-4819-40-1-111

[8] Devaney K, Goodman ZD, Epstein MS, et al. Hepatic Sarcoidosis Clinicopathologic Features in 100 Patients. Am J Surg Pathol. 1993; 17(12): 1272-1280. PMid: 8238735. https://doi.org/10.109 7/00000478-199312000-00009

[9] Ryrie DR. Sarcoidosis with Obstructive Jaundice. Proc R Soc Med. 1954; 47: 879. PMid: 13215528.

[10] Peyré CG, Wakim M, Mateo R, et al. Unusual cases of jaundice secondary to non-neoplastic bile duct obstruction. Am Surg. 2004; 70(7): 620-624. PMid: 15279187.

[11] Buxbaum J, Papademetriou M, Klipfel N, et al. Biliary sarcoidosis: Early diagnosis minimizes the need for surgery. Am J Respir Crit Care Med. 2013; 187(5): 556-559. PMid: 23457369. https: //doi.org/10.1164/ajrccm.187.5.556

[12] Alam I, Levenson SD, Ferrell LD, et al. Diffuse intrahepatic biliary strictures in sarcoidosis resembling sclerosing cholangitis: Case re- port and review of the literature. Dig Dis Sci. 1997; 42(6): 1295-1301. PMid: 9201098. https://doi.org/10.1023/A : 101887461216 6

[13] Tombazzi C, Waters B, Ismail MK, et al. Sarcoidosis mimicking primary sclerosing cholangitis requiring liver transplantation. Ann Hepatol. 2008; 7(2008): 83-86.

[14] Sotiropoulos GC, Dahmen U, Dirsch O, et al. Biliary tract obstruction due to sarcoidosis. Endoscopy. 2005; 37(12): 1262. PMid: 16329035 https://doi.org/10.1055/s-2005-921151

[15] Lloyd-Davies RW, Forbes GB. Sarcoidosis of the Gall Bladder. Gastroenterology. 1965; 49(3): 287-290. PMid: 5829842.

[16] Bloom R, Sybert A, Mascatello VJ. Granulomatous Biliary Tract Obstruction Due to Sarcoidosis - Report of a Case and Review of the Literature. Am Rev Respir Dis. 1978; 117: 783-787. PMid: 646224

[17] Freed JS, Reiner MA. Acute Cholecystitis as a Complication of Sarcoidosis. Arch Intern Med. 1983; 143: 2188-2189. https: //doi.org/10.1001/archinte.1983.00350110178037

[18] Toda K, Souda S, Yoshikawa Y, et al. Narrowing of the Distal Common Bile Duct and the Portal Vein Secondary to Pancreatic Sarcoidosis. Am J Gastroenterol. 1994; 89: 1259-1261. PMid: 8053449.

[19] Albu E, Saraiya RJ, Carvajal SJ, et al. Sarcoidosis Presenting as Obstructive Jaundice. Am Surg. 1995; 61(6): 516-517. PMid: 7762901.

[20] Rizeig MA, Fashir BM. Biliary Tract Obstruction Due to Sarcoidosis: A Case Report. Am J Gastroenterol. 1997; 92(3): 527-528.

[21] Mert A, Avsar S, Ozaras R, et al. Gall Bladder Involvement in Sarcoidosis. J Clin Gastroenterol. 2004; 38(7): 612-613. PMid: 15232369. https://doi.org/10.1097/00004836-200408000 $-00016$

[22] Maambo E, Brett AS, Vasudeva R, et al. Hepatobiliary Sarcoidosis Presenting as Sclerosing Cholangitis: Long-Term Follow-Up. Dig Dis Sci. 2007; 52(12): 3363-3365. PMid: 17394077. https : //doi.org/10.1007/s10620-006-9451-3

[23] Harder H, Büchler MW, Fröhlich B, et al. Extrapulmonary sarcoidosis of liver and pancreas: A case report and review of literature. World J Gastroenterol. 2007; 13(17): 2504-2509. PMid: 17552036. https://doi.org/10.3748/wjg.v13.i17.2504 